\title{
Vibrational Analysis and Non Linear Optical Activity of 3-fluoro-4-methylbenzonitrile
}

\author{
N. Y. SUGIRTHA SUNI ${ }^{1}$, L. GURU PRASAD ${ }^{2}$ and R. GANAPATHI RAMAN*1 \\ 'Department of Physics, 1 Nano Computational Laboratory, Department of Nano Technology, \\ Noorul Islam Centre for Higher Education, Kumaracoil-629180, Thuckalay, India. \\ ${ }^{2}$ Department of Science \& Humanities, M. Kumarasamy College of Engineering, Karur, India. \\ ${ }^{*}$ Corresponding author E-mail: ganapathiraman83@gmail.com
}

http://dx.doi.org/10.13005/ojc/340359

(Received: July 23, 2017; Accepted: March 9, 2018)

\begin{abstract}
The optimized molecular geometry, mulliken atomic charges, highest occupied molecular orbitals (HOMO) energy, lowest unoccupied molecular orbitals (LUMO) energy, polarizability and the first order hyperpolarizability of 3-fluoro-4-methylbenzonitrile has predicted with the help of quantum chemistry calculations by density functional theory (DFT) with B3LYP using 6-311++G(d,p) basis set. FTIR and FT-Raman spectra are investigated and compared with the observed data. Observed HOMO-LUMO energy gap offers the evidence for the presence of intermolecular interactions in the compound. First order hyperpolarizability calculated by quantum calculations infers that the title compound was an efficient tool for future applications in the field of non-linear optics. Natural bond orbitals and the thermodynamical properties were also studied by DFT.
\end{abstract}

Keywords: 3-fluoro-4-methylbenzonitrile, density functional theory (DFT), FTIR, FT-Raman, HOMO, LUMO.

\section{INTRODUCTION}

Benzonitrile is an aromatic organic compound. Derivatives of benzonitrile find application in industries and medical field (M. Alcolea Palafox, 2003). Benzonitrile compounds are used as preservatives for food products. They are used for making aniline blue a dye. In medical field many benzonitrile derivatives in solid form are used as urinary antiseptic and vapour form are used for disinfecting bronchial tubes (Hermann Imgartinger, 2000). Since the derivatives of benzonitrile have wide applications,many studies are reported on such compounds. First order hyperpolarizability and HOMO-LUMO energy are the most important tools to predict the NLO activity of a compound. Quantum chemistry calculations provides the entire information about the structural, vibrational, electronic, optical, thermodynamic and other related properties of a molecule (David Pegu, 2013). Hence the present analysis was carried out to study the molecular properties of 3-fluoro-4-methylbenzonitrile and to elucidate useful information about the molecule. 


\section{EXPERIMENTAL}

The compound 3-Fluoro-4-methyl benzonitrile (3F4MBN) was purchased from sigma-Aldrich Chemical Company, USA with a purity of not less than $99 \%$ and used as such for experimental studies. FT-Raman spectra of 3 F4MBN was inscribed using $1064 \mathrm{~nm}$ line of $\mathrm{Nd}$ :YAG laser as the exciting wavelength in range $50-3500 \mathrm{~cm}^{-1}$ on a EZRaman, Enwaveoptronics, USA IFS $66 \mathrm{~V}$ spectrometer. Fourier transform infrared (FTIR) spectra was inscribed using 8400 S Bruker, AlphaT,Germany infrared spectrophotometer using $\mathrm{KBr}$ pellet technique in the range $4000-400 \mathrm{~cm}^{-1}$. The spectra has been inscribed at normal temperature with a scanning speed $30 \mathrm{~cm}^{-1} \mathrm{~min}-1$.

\section{Computational}

All calculations has been met with Gaussian 09 program package [M.J. Frisch, 2009] with the aid of DFT with B3LYP using 6-311++G(d,p) basis set and results were viewed using GAUSS VIEW program. HOMO and LUMO energy was obtained from time dependent density functional theory. NBO analysis has been executed using same basis set to study molecular interaction between filled and vacant orbitals. Polarizability and hyperpolarizability were also calculated.

Table 1: Geometrical Parameters of 3--fluoro- 4-methylbenzonitrile

\begin{tabular}{|c|c|c|c|c|c|}
\hline Parameter & B3LYP & Parameter & B3LYP & Parameter & B3LYP \\
\hline BondLength $(\AA)$ & $6-311 \mathrm{G}++(\mathrm{d}, \mathrm{p})$ & Bond Angle $\left({ }^{\circ}\right)$ & $6-311 G++(d, p)$ & Dihedral angle & $6-311 G++(d, p)$ \\
\hline C1-C2 & 1.554 & $\mathrm{C} 2-\mathrm{C} 1-\mathrm{H} 11$ & 109.5741 & $\mathrm{H} 11-\mathrm{C} 1-\mathrm{C} 2-\mathrm{C} 3$ & -150.8946 \\
\hline $\mathrm{C} 1-\mathrm{H} 11$ & 1.0675 & $\mathrm{C} 2-\mathrm{C} 1-\mathrm{H} 12$ & 108.9205 & $\mathrm{H} 11-\mathrm{C} 1-\mathrm{C} 2-\mathrm{C} 7$ & 29.386 \\
\hline $\mathrm{C} 1-\mathrm{H} 12$ & 1.072 & $\mathrm{C} 2-\mathrm{C} 1-\mathrm{H} 13$ & 109.8545 & $\mathrm{H} 12-\mathrm{C} 1-\mathrm{C} 2-\mathrm{C} 3$ & 89.2887 \\
\hline $\mathrm{C} 1-\mathrm{H} 13$ & 1.0814 & $\mathrm{H} 11-\mathrm{C} 1-\mathrm{H} 12$ & 109.5449 & $\mathrm{H} 12-\mathrm{C} 1-\mathrm{C} 2-\mathrm{C} 7$ & -90.4308 \\
\hline C2-C3 & 1.3571 & $\mathrm{H} 11-\mathrm{C} 1-\mathrm{H} 13$ & 109.3711 & $\mathrm{H} 13-\mathrm{C} 1-\mathrm{C} 2-\mathrm{C} 3$ & -30.7176 \\
\hline $\mathrm{C} 2-\mathrm{C} 7$ & 1.5456 & $\mathrm{H} 12-\mathrm{C} 1-\mathrm{H} 13$ & 109.562 & $\mathrm{H} 13-\mathrm{C} 1-\mathrm{C} 2-\mathrm{C} 7$ & 149.563 \\
\hline C3-C4 & 1.5425 & C1-C2-C3 & 120.0591 & C1-C2-C3-C4 & -178.7972 \\
\hline C3-H14 & 1.0713 & C1-C2-C7 & 119.9809 & C1-C2-C3-H14 & 1.1997 \\
\hline C4-C5 & 1.3563 & C3-C2-C7 & 119.9594 & C7-C2-C3-C4 & 0.9223 \\
\hline $\mathrm{C} 4-\mathrm{H} 15$ & 1.0712 & C2-C3-C4 & 119.8227 & C7-C2-C3-H14 & -179.0808 \\
\hline C5-C6 & 1.5359 & C2-C3-H14 & 120.3491 & C1-C2-C7-C6 & 177.7006 \\
\hline C5-C9 & 1.5345 & C4-C3-H14 & 119.8282 & $\mathrm{C} 1-\mathrm{C} 2-\mathrm{C} 7-\mathrm{C} 8$ & -2.5711 \\
\hline $\mathrm{C6}-\mathrm{C} 7$ & 1.362 & C3-C4-C5 & 120.2109 & C3-C2-C7-C6 & -2.0191 \\
\hline $\mathrm{C} 6-\mathrm{H} 16$ & 1.0687 & $\mathrm{C} 3-\mathrm{C} 4-\mathrm{H} 15$ & 119.6262 & C3-C2-C7-C8 & 177.7092 \\
\hline C7-F8 & 1.3528 & C5-C4-H15 & 120.1614 & C2-C3-C4-C5 & 1.422 \\
\hline \multirow[t]{13}{*}{ C9-N10 } & 1.1563 & C4-C5-C6 & 120.064 & C2-C3-C4-H15 & -179.0196 \\
\hline & & C4-C5-C9 & 119.8784 & H14-C3-C4-C5 & -178.5748 \\
\hline & & C6-C5-C9 & 120.0563 & $\mathrm{H} 14-\mathrm{C} 3-\mathrm{C} 4-\mathrm{H} 15$ & 0.9835 \\
\hline & & C5-C6-C7 & 119.9799 & C3-C4-C5-C6 & -2.6347 \\
\hline & & C5-C6-H16 & 119.9932 & C3-C4-C5-C9 & 176.9544 \\
\hline & & C7-C6-H16 & 120.0269 & H15-C4-C5-C6 & 177.8093 \\
\hline & & C2-C7-C6 & 119.9001 & H15-C4-C5-C9 & -2.6016 \\
\hline & & C2-C7-F8 & 120.2341 & C4-C5-C6-C7 & 1.5281 \\
\hline & & C6-C7-C8 & 119.8652 & C4-C5-C6-H16 & -178.4505 \\
\hline & & & & C9-C5-C6-C7 & -178.0602 \\
\hline & & & & C9-C5-C6-H16 & 1.9612 \\
\hline & & & & $\begin{array}{l}\mathrm{C} 5-\mathrm{C} 6-\mathrm{C} 7-\mathrm{C} 2 \\
\mathrm{C} 5-\mathrm{C} 6-\mathrm{C} 7-\mathrm{C} 8\end{array}$ & $\begin{array}{c}0.8132 \\
-178.9161\end{array}$ \\
\hline & & & & $\mathrm{H} 16-\mathrm{C} 6-\mathrm{C} 7-\mathrm{C} 2$ & -179.2082 \\
\hline
\end{tabular}




\section{RESULTS AND DISCUSSION}

\section{Geometric Structure}

The optimized geometrical structure of 3-fluoro- 4-methylbenzonitrile is shown in Fig. 1. The optimized bond length, bond angle and dihedral angle are calculated using B3LYP $6-311++G(d, p)$ basis set. The geometrical parameters calculated are shown in Table 1. These parameters can be utilized to elucidate other parameters of the compound under investigation.

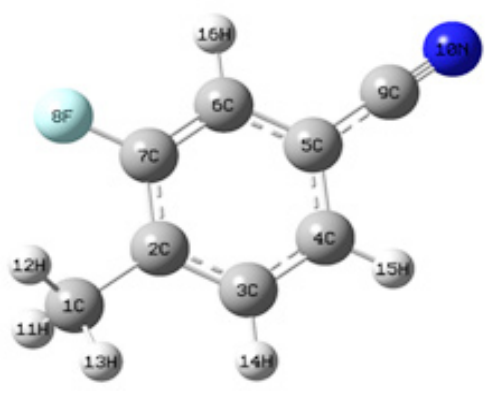

Fig.1.Optimized geometry of 3-fluoro-4-methyl benzonitrile

\section{Vibrational Analysis}

The investigated compound has 16 atoms and so it possess 42 normal modes of vibrations. Vibrational frequencies calculated and observed are shown in Table 2.

\section{C-H vibrations}

$\mathrm{C}-\mathrm{H}$ stretching vibrations in aromatic compounds appear in the range $3100-3000 \mathrm{~cm}^{-1}$ (M. Silverstein, 1989). In this study the peak at $3078 \mathrm{~cm}^{-1}$ and $3068 \mathrm{~cm}-1$ in the FTIR spectrum and FT-Raman Spectra respectively are ascribed to $\mathrm{C}-\mathrm{H}$ stretching vibrations. The corresponding calculated values are $3086 \mathrm{~cm}^{-1}$ and $3060 \mathrm{~cm}^{-1}$ which are in accordance with the observed values. For substituted benzenes, the three in-plane $\mathrm{C}$ - $\mathrm{H}$ vibrations appear in a range $1300-1000 \mathrm{~cm}^{-1}$ and three out-of-plane bending vibrations appear in a range $1000-750 \mathrm{~cm}^{-1}$ (J. Sharmi Kumar, 2015). The peaks at 1142, 1194, $1214,1252 \mathrm{~cm}^{-1}$ and at $1132,1200 \mathrm{~cm}^{-1}$ in the FTIR spectrum and FT-Raman Spectrum are ascribed to in-plane $\mathrm{C}-\mathrm{H}$ bending vibrations which are in accordance with the calculated values 1130,1171 , 1216 and $1276 \mathrm{~cm}^{-1}$. The peaks at 831,886 and 951 $\mathrm{cm}^{-1}$ and at $867,936 \mathrm{~cm}^{-1}$ in the FTIR spectrum in the FT-Raman Spectrum are ascribed to out- of -plane $\mathrm{C}-\mathrm{H}$ bending vibrations which are in accordance with the calculated values 836,896 and $950 \mathrm{~cm}^{-1}$.

\section{C-C vibrations}

Ring C-C stretchingvibration appears in a range $1650-1400 \mathrm{~cm}^{-1}$ (N. Sundaraganasan, 2009). Peaks at $1492 \mathrm{~cm}^{-1}, 1562 \mathrm{~cm}^{-1}$ and at $1494 \mathrm{~cm}^{-1}$, $1591 \mathrm{~cm}^{-1}$ in the FTIR spectrum and FT-Raman Spectrum are ascribed to C-C vibrations. The corresponding worked out values are $1494 \mathrm{~cm}^{-1}$, $1564 \mathrm{~cm}^{-1}$ and $1492 \mathrm{~cm}^{-1}, 1531 \mathrm{~cm}^{-1}$ which are in accordance with the observed data.

C-F vibrations: C-F vibration appears in the range $1360-1000 \mathrm{~cm}^{-1}$ (K. Sambathkumar, 2015). The sharp peak at $1270 \mathrm{~cm}^{-1}$ and at 1285 $\mathrm{cm}^{-1}$ in the FTIR spectrum and FT-Raman Spectra are ascribed to $\mathrm{C}-\mathrm{F}$ vibrations and are in accordance with calculated values $1270 \mathrm{~cm}^{-1}$ and $1276 \mathrm{~cm}^{-1}$.

$\mathrm{C} \equiv$ NVibrations: $\mathrm{C} \equiv \mathrm{N}$ vibration appears around $2200 \mathrm{~cm}^{-1}$ (S.Gunasekaran, 2006). The peak at $2244 \mathrm{~cm}^{-1}$ and at $2221 \mathrm{~cm}^{-1}$ in the FTIR spectrum and FT-Raman Spectra are ascribed to $\mathrm{C} \equiv \mathrm{N}$ vibrations which are in accordance with calculated values $2242 \mathrm{~cm}^{-1}$ and $2238 \mathrm{~cm}^{-1}$.

$\mathrm{CH}_{3}$ group vibrations: The title compound has only one substituted methyl $\left(\mathrm{CH}_{3}\right)$ group in the fourth position of the benzene ring. A methyl group is associated with nine fundamental mode of vibrations namely, the symmetric stretching mode $\left(\mathrm{CH}_{3}\right.$ sym. stretch), asymmetric stretching mode $\left(\mathrm{CH}_{3}\right.$ asym. stretch), in-plane hydrogen stretching mode, the symmetric deformation mode $\left(\mathrm{CH}_{3}\right.$ sym. deform), asymmetric deformation mode $\left(\mathrm{CH}_{3}\right.$ asy. deform), the in-plane rocking mode $\left(\mathrm{CH}_{3}\right.$ ipr), out-of-plane rocking mode $\left(\mathrm{CH}_{3}\right.$ opr) and twisting $\left(\mathrm{tCH}_{3}\right)$ mode. Substituted methyl groups in the aromatic ring systems are typically specified as electron donating groups (D. Lin-Vein, 1991).

Generally $\mathrm{CH}_{3}$ vibration appear in a range (2900-3000 $\mathrm{cm}^{-1}$ ) (M. Murugan, 2012). Peak at $3000 \mathrm{~cm}^{-1}$ and at $2986 \mathrm{~cm}^{-1}$ in the FTIR spectrum and FT-Raman Spectra are ascribed to $\mathrm{CH}_{3}$ symmetrical stretching mode vibration which are in accordance with the calculated value $3035 \mathrm{~cm}^{-1}$. The peak at $1499 \mathrm{~cm}^{-1}$ in the FTIR spectrum corresponds to $\mathrm{CH} 3$ in plane bending modes which is in accordance with the calculated value $1492 \mathrm{~cm}^{-1}$. The peak at $1069 \mathrm{~cm}^{-1}$ in the FTIR spectra harmonize to $\mathrm{CH}_{3}$ in rocking mode vibration which is in accordance with the calculated value $1060 \mathrm{~cm}^{-1}$. 
Table 2: Observed and calculated (FT-IR, FT-Raman) vibrational frequencies of the title compound

\begin{tabular}{|c|c|c|c|c|c|c|c|}
\hline Mode & Label & $\begin{array}{c}\text { Experimental } \\
\left(\mathrm{cm}^{-1}\right) \mathrm{FT}-\mathrm{IR}\end{array}$ & FT-Raman & $\begin{array}{c}\text { B3LYP/6- } \\
311++G(d, p)\end{array}$ & $\begin{array}{l}\text { IR Intensity } \\
(\mathrm{Km} / \mathrm{mol})\end{array}$ & $\begin{array}{l}\text { Raman } \\
\text { Activity }\end{array}$ & $\begin{array}{l}\text { Vibrational } \\
\text { assignments }\end{array}$ \\
\hline 1 & A & & & 95.7103 & 0.0009 & 0.3696 & $\tau \mathrm{CH}_{3}$ \\
\hline 2 & A & & & 104.1663 & 1.438 & 0.4454 & $\tau \mathrm{C} \equiv \mathrm{N}$ \\
\hline 3 & A & & 154 & 148.0831 & 5.0946 & 3.2263 & $\beta C \equiv N$ \\
\hline 4 & A & & 194 & 197.8587 & 3.2846 & 1.3948 & $\gamma \mathrm{C}-\mathrm{CH}_{3}+\gamma \mathrm{C} \equiv \mathrm{N}$ \\
\hline 5 & A & & 273.7 & 276.2751 & 2.2767 & 0.3873 & $\beta \mathrm{C}-\mathrm{CH}_{2}+\beta \mathrm{C}-\mathrm{F}$ \\
\hline 6 & A & & 280 & 282.9399 & 2.3928 & 0.6734 & $\omega \mathrm{C}-\mathrm{F}$ \\
\hline 7 & A & & 414 & 409.8928 & 1.4935 & 4.0477 & $\gamma \mathrm{C}-\mathrm{CH}_{3}$ \\
\hline 8 & A & & 423 & 432.2994 & 1.4908 & 3.9706 & $16 \mathrm{a} \gamma \mathrm{C}-\mathrm{C}-\mathrm{C}$ \\
\hline 9 & A & & 434 & 436.6913 & 1.945 & 1.5209 & $\beta C-C-C$ \\
\hline 10 & A & 513.3 & 462.6 & 491.5191 & 2.5994 & 1.6762 & $16 \mathrm{~b} \gamma \mathrm{C}-\mathrm{C}-\mathrm{C}$ \\
\hline 11 & A & 560.4 & 544 & 545.9524 & 3.7765 & 7.3407 & $16 \mathrm{~b} \beta \mathrm{C}-\mathrm{C}-\mathrm{C}$ \\
\hline 12 & A & 611.8 & 615.8 & 603.8151 & 2.6259 & 0.9818 & $16 a \beta C-C-C$ \\
\hline 13 & A & 632.4 & 620 & 643.1389 & 10.0649 & 1.2955 & $6 a \delta$ \\
\hline 14 & A & & 685.8 & 700.6038 & 0.7185 & 2.4935 & $\gamma \mathrm{C}-\mathrm{C}-\mathrm{C}+\mathrm{t} \mathrm{C} \equiv \mathrm{N}$ \\
\hline 15 & A & 753.2 & 754 & 713.601 & 1.7294 & 0.3961 & $\gamma \mathrm{C}-\mathrm{C}-\mathrm{C}+\mathrm{t} \mathrm{C} \equiv \mathrm{N}$ \\
\hline 16 & A & 768.3 & & 769.1046 & 5.0664 & 24.505 & $\beta C-C-C+t$ C-F \\
\hline 17 & A & 831.4 & & 836.704 & 23.2161 & 0.1268 & $17 \mathrm{~b} \gamma \mathrm{C}-\mathrm{H}$ \\
\hline 18 & A & 886.4 & 867 & 896.4401 & 24.4011 & 0.1313 & $\gamma \mathrm{C}-\mathrm{H}+\tau \mathrm{C} \equiv \mathrm{N}$ \\
\hline 19 & A & 951.45 & 936 & 950.8395 & 21.1946 & 4.5349 & $10 \mathrm{a} \gamma \mathrm{C}-\mathrm{H}$ \\
\hline 20 & A & 993.8 & & 970.5941 & 0.0134 & 0.0512 & Ring breathing \\
\hline 21 & A & 1007.4 & 1006 & 1019.558 & 18.0624 & 0.9225 & $\begin{array}{l}\text { Trigonal } \\
\text { bending }\end{array}$ \\
\hline 22 & A & 1069 & & 1060.461 & 2.6859 & 0.0411 & $\rho \mathrm{CH}_{3}$ \\
\hline 23 & A & 1142.5 & 1132 & 1130.859 & 36.0379 & 19.7862 & $\beta \mathrm{CH}+\mathrm{vC}^{3}-\mathrm{F}$ \\
\hline 24 & A & 1194.9 & & 1171.555 & 0.575 & 3.0025 & $\beta \mathrm{CH}$ \\
\hline 25 & A & 1214.5 & 1200 & 1216.88 & 3.7437 & 1.9298 & $\beta \mathrm{CH}+v \mathrm{C}-\mathrm{F}$ \\
\hline 26 & A & 1270.4 & 1277 & 1276.279 & 78.5627 & 76.1255 & $\beta \mathrm{CH}$ \\
\hline 27 & A & & 1285 & 1295.275 & 1.0495 & 1.5283 & vC-F \\
\hline 28 & A & & 1332 & 1329.431 & 0.409 & 2.3016 & $\gamma \mathrm{C}-\mathrm{CH}_{3}$ \\
\hline 29 & A & 1429.5 & 1410 & 1419.072 & 3.2555 & 20.0889 & $\begin{array}{c}\mathrm{CH}_{3} \text { asym. } \\
\text { deform }\end{array}$ \\
\hline 30 & A & 1469.5 & & 1439.191 & 29.835 & 0.7039 & $\begin{array}{c}\mathrm{CH}_{3} \text { asym. } \\
\text { deform }\end{array}$ \\
\hline 31 & A & 1472 & 1487 & 1480.588 & 8.2457 & 9.5451 & 14vC-C \\
\hline 32 & $A$ & 1499 & & 1492.38 & 8.7334 & 13.1925 & $\mathrm{BCH}_{3}$ \\
\hline 33 & A & 1572.6 & 1584.7 & 1531.799 & 50.2532 & 1.5091 & 19avC-C \\
\hline 34 & A & 1600 & & 1601.005 & 40.2309 & 2.2114 & $\begin{array}{l}\text { 8buC-C (semi- } \\
\text { circle stretch) }\end{array}$ \\
\hline 35 & A & 1668.6 & 1658 & 1656.248 & 2.154 & 172.8537 & $8 a v C-C$ \\
\hline 36 & A & 2338 & 2338 & 2333.982 & 43.5827 & 557.747 & $\gamma \mathrm{C} \equiv \mathrm{N}$ \\
\hline 37 & A & 3000 & 2986 & 3035.594 & 15.3871 & 306.9231 & vsym $\mathrm{CH}_{3}$ \\
\hline 38 & A & 3078 & 3053 & 3086.357 & 8.4141 & 99.1312 & $\begin{array}{c}20 \mathrm{a}^{* *} \text { arom. } \\
\text { vC-H }\end{array}$ \\
\hline 39 & A & 3117 & 3108 & 3118.279 & 12.3515 & 65.7333 & vC-H \\
\hline 40 & $A$ & 3178 & & 3177.419 & 5.5481 & 75.475 & vC-H \\
\hline 41 & A & 3203 & 3207 & 3203.313 & 1.539 & 102.9211 & UC-H \\
\hline 42 & A & 3221 & & 3212.26 & 0.7115 & 88.4629 & vC-H \\
\hline
\end{tabular}

v-stretching; $v_{\text {sym }}$-symmetrical stretching; $v_{\text {asy }}$ - asymmetrical stretching; $\beta$-in plane bending; $\gamma$-out-of-plane bending; $\omega$-wagging; t-twisting; $\delta$-scissoring; $\tau$-torsion; $\rho$-rocking; *-wilson's notion; IR int-IR intensities. 


\section{Mulliken atomic Charges}

The scope of bonding of a molecule depend on the number of unpaired electrons in the atoms and hence the atomic charges has been retrieved by Mulliken population assay (A. A. Popov, 2004). Mulliken atomic Charges calculation plays an important part in applying quantum chemistry calculation to molecular systems because atomic charge affects dipole moments, polarizability, electronic structures and other properties of molecular systems (R. S. Mulliken, 1985). Mulliken charges obtained using B3LYP 6-311++G (d,p) are shown in Table 3. Mulliken atomic charges graph is shown in Fig.2. All hydrogen atoms exhibits positive charge, nitrogen and fluorine atom exhibit negative charge. This suggests the creation of intermolecular interaction in solid forms(Isa Sidir, 2010). From the charge calculation it is clear that nitrogen atom having negative charge acts as donor atom and the ring hydrogen atom having positive charge acts as acceptor atoms.
Table 3: Mulliken Population

Analysis of 3--fluoro-4methylbenzonitrile

\begin{tabular}{ccc}
\hline SI.No & Atoms & B3LYP \\
\hline 1 & $\mathrm{C}$ & -0.38354 \\
2 & $\mathrm{C}$ & 1.303938 \\
3 & $\mathrm{C}$ & -0.85876 \\
4 & $\mathrm{C}$ & -0.53413 \\
5 & $\mathrm{C}$ & 2.179886 \\
6 & $\mathrm{C}$ & -0.15444 \\
7 & $\mathrm{C}$ & -0.68165 \\
8 & $\mathrm{~F}$ & -0.17206 \\
9 & $\mathrm{C}$ & -1.58496 \\
10 & $\mathrm{~N}$ & -0.1711 \\
11 & $\mathrm{H}$ & 0.178828 \\
12 & $\mathrm{H}$ & 0.17881 \\
13 & $\mathrm{H}$ & 0.157086 \\
14 & $\mathrm{H}$ & 0.143043 \\
15 & $\mathrm{H}$ & 0.190491 \\
16 & $\mathrm{H}$ & 0.208561 \\
\hline
\end{tabular}

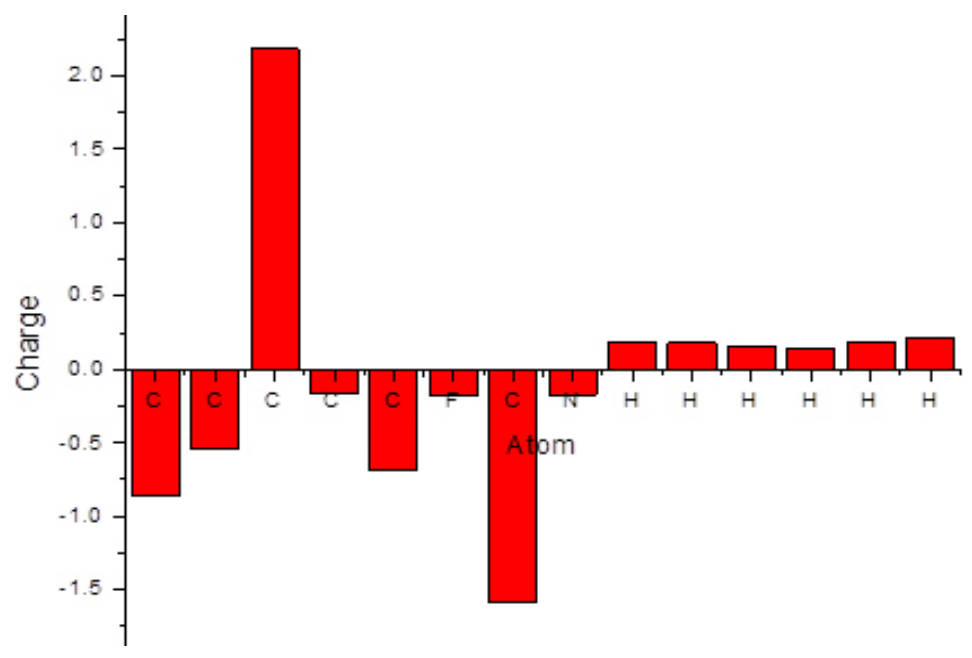

Fig. 2. A plot of Mulliken atomic charges of 3--fluoro- 4-methylbenzonitrile

\section{Polarizability and Hyperpolarizability}

The reaction of systems in applied electric fields has been explained by its Polarizability and hyperpolarizability. The non linear optical property of a compound can be studied using these parameters. The investigated first order hyperpolarizability of investigated compound is $2.768 \times 10^{-30}$ esu which is 9 times urea $\left(0.2991 \times 10^{-30} \mathrm{esu}\right)$ a standard NLO material (Li Xiao-Hong, 2011). Calculated dipole moment, polarizability and hyperpolarizability are given in Table 4.

\section{HOMO LUMO analysis}

HOMO stands for highest occupied molecular orbital which represents the ability of a molecule to donate an electron and LUMO stands for lowest unoccupied molecular orbital which represents the ability of a molecule to accept 
an electron. HOMO and LUMO are the major orbitals that take part in the chemical stability of the molecule (J. A. Alanso, 2004). The calculated

Table 4: Electric dipole moment, polarizability and hyperpolarizability of 3--fluoro4-methylbenzonitrile

\begin{tabular}{cc}
\hline Parameters & B BLYP \\
& $6-311++\mathrm{G}(\mathrm{d}, \mathrm{p})$ \\
\hline$\mu_{\mathrm{x}}$ & 0.5802156 \\
$\mu_{\mathrm{y}}$ & 0.010185 \\
$\mu_{z}$ & -1.7797845 \\
$\mu=$ & $1.87200 \mathrm{Debye}$ \\
$\alpha_{\mathrm{xx}}$ & 92.0760016 \\
$\alpha_{\mathrm{xy}}$ & -0.0391977 \\
$\alpha_{\mathrm{yy}}$ & 54.1494 \\
$\alpha_{\mathrm{xz}}$ & 0.300154 \\
$\alpha_{\mathrm{yz}}$ & -0.5182233 \\
$\alpha_{z z}$ & 145.5895464 \\
$\alpha_{0}$ & $194.7552 \times 10^{-33} \mathrm{esu}$ \\
$\alpha=$ & $1682.549 \times 10^{-33} \mathrm{esu}$ \\
$\beta_{\mathrm{xxx}}$ & 103.2968388 \\
$\beta_{x x y}$ & -7.7277807 \\
$\beta_{x y y}$ & 34.3821757 \\
$\beta_{y y y}$ & 6.763047 \\
$\beta_{x x z}$ & 24.3731807 \\
$\beta_{x y z}$ & 0.135037 \\
$\beta_{y y z}$ & -18.6541887 \\
$\beta_{x z z}$ & 28.6181066 \\
$\beta_{y z z}$ & 5.1407 \\
$\beta_{z z z}$ & 268.1870903 \\
$\beta_{0}$ & $2768.5784 \times 10^{-33} \mathrm{esu}$ \\
\hline & \\
\hline
\end{tabular}

Table 5: Calculated energies of 3--fluoro4-methylbenzonitrile

\begin{tabular}{lc}
\hline LUMO & -1.79 \\
\hline HOMO & -7.4 \\
Energy Gap & 5.61 \\
Electronegativity $(\chi)$ & -4.595 \\
Chemical Potential $(\mu)$ & 4.595 \\
Global Hardness $(\eta)$ & 2.805 \\
Global softness $(s)$ & 0.356506239 \\
Electrophilicity Index $(\omega)$ & 6.4444875 \\
EHOMO-1 $(\mathrm{eV})$ & -7.82 \\
ELUMO+1(eV) & -1.36 \\
EHOMO-1 - ELUMO+1 $(\mathrm{eV})$ & -6.46 \\
\hline
\end{tabular}

HOMO LUMO gap using B3LYP 6-311++G(d,p) is $5.61 \mathrm{eV}$. The HOMO LUMO energy gap explain that the title compound is experiencing charge transfer interactions and it reflects its NLO property (Basak Kosar, 2011). The calculated energy values are shown in Table 5.

\section{Thermodynamic parameters}

Several thermodynamical parameters has been calculated and are listed in Table 6 . Scale factors were recommended (Zeynep Demircioglu, 2014) for calculating zero point vibrational energy and entropy accurately. Changes in total energy and entropy at normal temperature are presented in Table. 6. These changes seems to be insignificant.

Table 6: Thermodynamic parameters

\begin{tabular}{lc}
\hline $\begin{array}{l}\text { Thermodynamic } \\
\text { functions of DMAP }\end{array}$ & B3LYP \\
& $6-311++\mathrm{G}(\mathrm{d}, \mathrm{p})$ \\
\hline Self-consistent field & -463.132 \\
energy (a.u) & \\
Zero point vibrational & 74.043 \\
energy (kcal/mol) & \\
Rotational constant (GHz) & 3.021 \\
& 0.880 \\
& 0.684 \\
Rotational temperature (K) & 0.145 \\
& 0.042 \\
Thermal energy (kcal/mol) & 0.033 \\
Total & \\
Translational & 79.491 \\
Rotational & 0.889 \\
Vibrational & 0.889 \\
Specific heat capacity at constant & 77.714 \\
volume (cal/mol K) & \\
Total & \\
Translational & 32.233 \\
Rotational & 2.981 \\
Vibrational & 2.981 \\
Dipole moment (Debye) & 26.271 \\
Lumo(eV) & 4.7644 \\
Homo(eV) & -1.79 \\
Energy gap(eV) & -7.4 \\
Entropy(S)(cal/mol K) & -5.61 \\
Total & \\
Translational & 91.514 \\
Rotational & 40.614 \\
Vibrational & 29.559 \\
Gibbs Free Energy & 21.342 \\
Enthalpy & 0.084 \\
\hline & 0.128 \\
\hline
\end{tabular}




\section{Non linear optical activity}

NLO activity give key function for properties like the frequency shifting, optical modulation, optical swaping, optical logic for the extending technology in the field of communications, signal processings and optical inter-connections (Mauricio Alcolea Palafox, 2000). Molecules that exhibit asymmetric polarization which is induced because of electron donars and acceptors in the pi-electron conjugatedsystems are efficient materials for electro-optics and NLO applications (I. Khan, 2013). In order to find the non linear activity of the material, first order hyperpolarizability of the investigated compound was calculated and compared with urea, a standard NLO material. It was found that the first order hyperpolarizability of our investigated compound is 9 times than urea. Hence we propose that the investigated compound under study is an efficient material for future NLO applications.

\section{CONCLUSION}

Detailed investigation of the structural and electronic property of the compound under study has been performed by DFT using suitable basis set. Calculated first order hyperpolarizability and HOMO-LUMO energy gap confirmed the NLO property of the compound. First order hyperpolarizability calculated for the compound is 9 times greater than urea. Hence the compound under study is an efficient material for future NLO applications. Mulliken atomic charge calculation suggests that there is charge transfer from $\mathrm{N}, \mathrm{F}$ to $\mathrm{H}$.

\section{REFERENCES}

1. Alcolea Palafox M, Rastogi V. K., Mittal L. "Benzonitriles: Survey of their importance and scaling of their vibrational frequencies," Int. J.Quantum Chem., 2003, 94, 189-204.

2. Imgartinger Hermann, Fettel Peter Walter, EscherThomas, Tinnefeld Philip, Nord Simon, and Saucer Markus "Substituent effects on Redox properties and photoinduced electron transfer in Isoxazolo Fullerenes," Eur. J.Org. Chem., 2000, 2000, 455-465.

3. Pegu David and Singh Bedamani Ngangbam, "Quantum Chemical Calculations of Molecular Structure, Electronic, Thermodynamic and Non-linear optical properties of 2-amino3-nitro-6-methylpyridine,"Int.J.Advanced Research., 2013, 1(9), 531-538.

4. Frisch M. J., GAUSSIAN 09, Revision A. 9, Gaussian, INC, Pittsburgh, 2009.

5. Silverstein M., Basseler G.C., Morill C., Spectrometric Identification of Organic Compounds, Wiley, New York, 1981.

6. Sharmi Kumar J., Renuga Devi T.S., Ram Kumaar G.R., Bright A., "Ab initio and density functional theory calculations of molecular structure and vibrational spectra of 4-(2-Hydroxyethyl) piperazine1-ethanesulfonic acid," Spectrochimica Acta PartA: Molecular and Biomolecular Spectroscopy., 2015, 152, 509-522.

7. Sundaraganasan N., Elango G., Sebastian S., \& Subramani P., Ind. J. Pure App. Phy.,
2009, 47, 481.

8. Sambathkumar K., Jeyavijayan S., Arivazhagan M., Spectrochim. Acta Part A Mol. Biomol. Spectrosc., 2015, 147, 124.

9. Gunasekaran S., Seshadri S., Muthu S., Indian J. Pure and Applied Physics., 2006, 44, 360-366.

10. Lin-Vein D., Colthup N.B., Fateley W. G., Grasselli J.G., "The Handbook of Infrared and Raman Characteristics Frequencies of Organic Molecules, Academic Press, San Diego, CA, 1991.

11. Murugan M., Balachandran V. and Marana, "Vibrational spectra and electrostatic potential surface of 2-fluoro-6-methoxybenzonitrile based on quantum chemical calculations," J.Chemical and Pharmaceutical Research., 2012, 4(7), 3400-3413.

12. Popov A. A., Senyavin V. M., Ganovsky A. A., Chem. Phys. Lett., 2004, 383, 149-155

13. Mulliken R. S., J. Chem. Phys., 1985, 23, 1833-1840, .

14. Sidir Isa, Sidir Gulseven Yadigar, Kumalar Mustafa, Erol Tasal, "Ab initio Hartree-Fock and density functional theory investigations on the conformational stability, molecular structure and vibrational spectra of 7-acetoxy6-(2, 3-dibromopropyl)-4, 8-dimethyl conmarin molecule," J. Mol. Struct., 2010, 964, 134-151.

15. Xiao-Hong Li, Xiang-Ru Liu, Xian-Zhou Zhang, "Calculation of vibrational spectroscopic and 
NMR parameters of 2- Dicyanovinyl-5-(4-N, $\mathrm{N}$ - dimethyl aminophenyl) thiophene by ab initio HF and density functional methods," Comput. Theor. Chem., 2011, 969, 27-34.

16. Alanso J. A., Balbas L.C. and Rubio A., "Non local functional for exchange and correlation in density functional theory Application to atoms and to small atomic clusters," Int. J. Quantum Chem., 2004, 56, 499-508.

17. Kosar Basak, Albayrak C., "Spectroscopic investigations and quantum chemical compound study of (E)-4-methoxy-2-[ptolylimino) methyl] phenol,"Spectrochim Acta.,
2011, 78, 160-167.

18. Demircioglu Zeynep, Albayrak Cigdem, Buyukgungor Orhan, "Experimental (X-ray,FTIR and UV-Vis spectra) and theoretical methods (DFT study) of (E)-3 -methoxy -2-[p-tolylimino) methyl ] phenol," Spectrochim Acta., 2014 , 128, 748-758.

19. fox Pala Mauricio Alcolea,"Scaling factors for the prediction of vibrational spectra .I. Benzen molecule," Int. J. Quantum Chem., 2000, 77, 661-684.

20. Khan I, Ahmad A, J. Phys. Chem. Solid., 2013, 74, 1818. 